\title{
From Editor-in-Chief: issue insight, research education and encouraging scientific debate
}

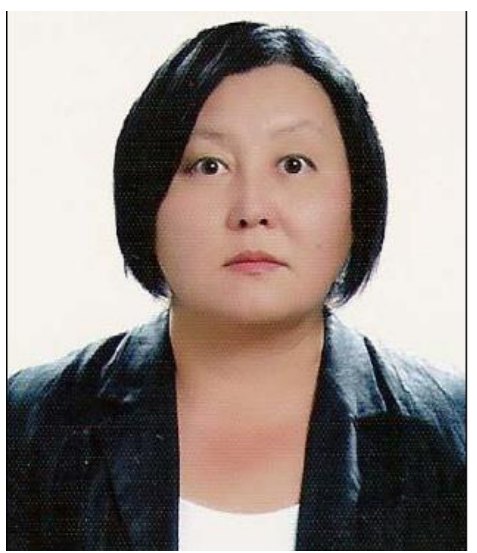

Dear Readers,

In this June 2018 issue of the Heart Vessels and Transplantation you can find the editorials on comprehensive treatment of infective endocarditis and development of approaches in research evaluation and career advancement requirements in Kyrgyz Republic, prepared by the editors of our journal; the review on the management of valvular heart diseases in elderly and research article on candidemia in cardiothoracic intensive care unit and detectability of congenital heart diseases in Kyrgyzstan; as well as the quiz on electrocardiography.

We also announce the educational activity our journal is involved- International Research Interdisciplinary School (program developed at Duke University, Durham, NC, USA) that will be held on the shore of Issyk-Kul, Kyrgyzstan in June 2018, this is the second school in our country, which was held in many countries all over the globe and will help young researchers, residents and fellows, junior faculty members in medicine, and all relevant disciplines to enhance their research skills in preparation of international research projects, their theses and dissertations, but also to read guidelines and understand the evidence-based recommendations, apply them in their clinical practice even they are not involved in research. We would like to remind that the approach is very different from traditional teaching, and provides essential skills and directions how to do research to participants who are very busy with their main work schedule, having little time at hospitals and universities, especially at medical faculties where the training how to do research is not taught, but many medical professional societies include now in their programs requirements for scholarly activity. Different professional societies are in attempt to include rotations on scholarly activity, provide lectures or just working with supervisors; the research school differs by method of teaching like taking off the participants from their routine and immersing intensively in training for few days. The outcomes of this research practicum were already presented in articles summarizing the approach, goals and providing the statistics on growth of publications and citations of participants since first year it was held in 2006. You can find more information also in editorials prepared by our editors in previous issues of our journal.

I would like also to inform you that more editorials, educational articles are being prepared by our editors summarizing advancements in their field of expertise scheduled for publication in further issues. We as editors responding to our requests working hard on providing the reviews and educational materials, editorials, but we want to hear your voice readers, your opinions as well.

Thus, we encourage all readers, senior or junior faculty members or residents and fellows in training to write, share with editors without restrictions and express their opinions freely on published research articles or case reports, critically address the weaknesses and strengths of the studies or share their knowledge on the topic of research or clinical management of challenging cases or images. This is essential to every journal to have an unrestricted feedback and scientific debate. We will provide fair unbiased management of these debates and publish both letters and responses of authors. Therefore, you will contribute to current evidence-based knowledge and attain your skills in scientific debates. We also look forward for all types of articles - you can find now extended disciplines and types of articles we consider for publication in aims and scope and instructions for authors.

Responding to the attempts to access the article submission system, as we noticed from our statistics of accesses, I would like to remind that our team is working on article submission system, meanwhile you can send articles by email and if you have difficulties in communication you can use the form provided on website, denoting your email address so we can respond.

Gulmira Kudaiberdieva Editor-in-Chief

Heart Vessels and Transplantation

Peer-review: Internal

Conflict of interest: None to declare

Authorship: G.K.

Acknowledgement and funding: None to declare

Address for correspondence: Gulmira Kudaiberdieva, Editor-in-Chief, Heart Vessels and Transplantation, Email: editor@hvt-journal.com 